\title{
Đo lường sự thích nghi văn hóa xã hội của trí thức trẻ nhập cư vào Thành phố Hồ Chí Minh
}

\section{Measuring the sociocultural adaptation of young intellectuals in Ho Chi Minh City}

\author{
Chu Nguyễn Mộng Ngọc ${ }^{1 *}$, Hoàng Trọng ${ }^{1}$, Bùi Thị Thu Mỹ ${ }^{1}$ \\ ${ }^{1}$ Trường Đại học Kinh tế Thành phố Hồ Chí Minh, Việt Nam \\ *Tác giả liên hệ, Email: chunguyenmongngoc@ueh.edu.vn
}

THÔNG TIN
DOI: 10.46223/HCMCOUJS.
econ.vi.13.3.500.2018
Ngày nhận: 07/06/2018
Ngày nhận lại: 28/07/2018
Duyệt đăng: 31/10/2018
Tù khóa:
khái niệm hai cấp dạng phản
ánh, phương pháp tiếp cận
lặp lại mục hỏi, PLS-Sem, sự
thích nghi văn hóa xã hội

TÓM TÁ̀T

Di cư lao động là xu hướng tất yếu trên toàn cầu ngày nay. Với Thành phố Hồ Chí Minh (TP.HCM), lao động nhập cư là động lực quan trọng giải quyết vấn đề nhân lực, góp phần tăng cường, phát triển kinh tế thành phố. Nghiên cứu này đã phát triển mô hình đo lường khái niệm thích nghi văn hóa xã hội vào bối cảnh Việt Nam (VN), nhằm cung cấp một sự hiểu biết thấu đáo hơn về cách thức thích nghi của người nhập cư trí thức trẻ với đời sống tại TP.HCM. Phương pháp mô hình phương trình cấu trúc bình phương bé nhất từng phần (PLS-Sem) được dùng trong quá trình phân tích dữ liệu đã phát hiện năm thành phần phản ánh quá trình thích nghi văn hóa xã hội của người nhập cư trí thức trẻ và khẳng định quan hệ nhân quả giữa sự thích nghi với sự hài lòng về cuộc sống của người nhập cư. Các tác giả cũng gợi ý biện pháp để gia tăng khả năng thích nghi của người nhập cư trí thức trẻ tại TP.HCM.

\section{ABSTRACT}

Nowadays, labour migration is an inevitable trend all over the world. For Ho Chi Minh City, the migrant workforce is an important driver to help solve its shortage of human resources and enhance its economic growth. This research adapted the measurement of sociocultural adaptation in the Vietnamese context to gain a more thorough understanding of how young intellectuals adapt themselves to a new life in Ho Chi Minh City. This paper used partial least squares structural equation modeling (PLS-Sem) procedure to explore five components of the

Keywords:

PLS-Sem, reflective second order construct, repeated indicator approach, sociocultural adaptation sociocultural adaptation construct of young intellectuals and confirm the causal relationship between their adaptation and satisfaction. Then, some recommendations were also made to help increase young intellectuals' ability in sociocultural adaptation. 


\section{Giới thiệu}

TP.HCM là một trong những trung tâm kinh tế, văn hóa và giáo dục quan trọng của Việt Nam. Sức hút của một thành phố đang phát triển cùng với xu hướng đô thị hóa đã tạo nên những dòng người từ nhiều nơi chuyển đến sinh sống tại đây. Lâu nay vẫn có định kiến rằng nhập cư chỉ toàn những người có học vấn thấp, nhưng theo số liệu của Cục thống kê TP.HCM, năm 2004, tỉ lệ đại học và cao đẳng chiếm 9,15\% người đang tạm trú tại thành phố, trong khi tỉ lệ đại học và cao đẳng của cư dân lâu đời tại TP.HCM chỉ đạt 7,8\%.

Báo cáo phát triển con người của Liên Hiệp Quốc năm 2009 cho thấy dân nhập cư đã đóng góp đến $30 \%$ GDP của TP.HCM và tỉ lệ đó không giảm đi mà ngày càng tăng theo tốc độ di dân. Báo cáo này cũng chỉ ra người nhập cư là động lực quan trọng cho sự phát triển kinh tế xã hội song cho đến nay, những đóng góp của họ chưa được ghi nhận đầy đủ. Ngoài ra, nhiều người nhập cư rất khó thích nghi, dễ bị tổn thương và cần được sự quan tâm đặc biệt của các nhà hoạch định chính sách.

Để đóng góp hiệu quả vào sự phát triển của TP.HCM, người nhập cư cần phải thích nghi và hòa nhập với cuộc sống đô thị nhộn nhịp của TP.HCM. Hiện tại, theo khảo cứu của tác giả, ở TP.HCM chưa có nghiên cứu nào đo lường sự thích nghi văn hóa xã hội của người nhập cư trí thức, cũng như tác động của rào cản phân biệt (tâm lý-hành vi-chính sách...) đến quá trình ổn định đời sống cũng như sự hài lòng với cuộc sống của họ. Chính vì thế tác giả đã tiến hành đo lường sự thích nghi văn hóa xã hội của trí thức trẻ nhập cư vào TP.HCM. Nghiên cứu này có ý nghĩa đối với các nhà hoạch định chính sách trong các lĩnh vực của đời sống kinh tế xã hội cũng như chính với bản thân người nhập cư nhằm giúp những người nhập cư trí thức nâng cao khả năng thích nghi khi đến sống tại TP.HCM, để từ đó góp phần hiệu quả hơn vào sự phát triển của thành phố.

\subsection{Mục tiêu nghiên cúu}

Phát triển việc đo lường khái niệm Sự thích nghi văn hóa xã hội của người nhập cư trên tình huống trí thức trẻ nhập cư tại TP.HCM.

Kiểm tra mối quan hệ nhân quả giữa các yếu tố thích nghi văn hóa xã hội với sự phân biệt cảm nhận và sự hài lòng trong cuộc sống của người nhập cư trí thức trẻ.

Đề xuất những giải pháp để gia tăng khả năng thích nghi của người trí thức trẻ nhập cư vào TP.HCM cũng như những giải pháp về quản lý để phát huy tối đa tiềm năng con người của họ.

\section{2. Đối tựng, phạm vi nghiên cúu}

Đối tượng nghiên cứu là những người trí thức trẻ đang sống và làm việc tại thành phố từ 6 tháng đến 10 năm (để họ có thời gian trải nghiệm cuộc sống tại TP.HCM đủ dài) và có nơi sinh ra và lớn lên không phải là TP.HCM (quá trình này tính từ 0 đến dưới 18 tuổi). Việc lựa chọn độ tuổi cho đối tượng nghiên cứu căn cứ trên quan điểm của Tran (2013) chia người trưởng thành trẻ tuổi thành hai thời kì trong đó thời kì thứ hai của người trưởng thành tính từ sau 25 tuổi đến 40 tuổi là thời kì lập thân và lập nghiệp. Một trí thức trẻ ở độ tuổi này sẽ hội đủ những tố chất cần thiết về sức khỏe lẫn trí tuệ để tạo ra những đóng góp có giá trị đối với nền kinh tế 
xã hội của TP.HCM. Đó là lý do nghiên cứu xác định phạm vi tuổi của đối tượng khảo sát là từ 25 tuổi đến 40 tuổi.

\section{Cơ sở lý thuyết}

\section{Đo lường khái niệm Sự thích nghi văn hóa xã hội và thang đo SCAS}

Việc đo lường Sự thích nghi văn hóa xã hội (viết tắt Sự TNVHXH) như một kết quả của năng lực văn hóa dựa trên sự thích nghi có tính hành vi, có lẽ được phát hiện đầu tiên từ công trình của Argyle và các đồng nghiệp về năng lực xã hội, trong đó mức độ tự báo cáo về những khó khăn được đo lường như là một chỉ số về kỹ năng xã hội qua các tình huống như: tình huống yêu cầu sự quyết đoán, tình huống xã hội trang trọng, và tình huống gặp người lạ mặt (Argyle, 1969; Argyle, Furnham, \& Graham, 1981; Trower, Bryant, \& Argyle, 1978 as cited by Wilson, 2013).

Searle và Ward (1990) đã sửa đổi cách đo lường này, gọi là Thang đo khả năng tình huống xã hội để tạo ra phiên bản đầu tiên của Thang đo sự TNVHXH (Sociocultural Adaptation scale gọi tắt là SCAS).

SCAS được định nghĩa là sự tiếp nhận các kỹ năng hành vi cần thiết với một cá nhân để sắp xếp cuộc sống trong môi trường giao thoa văn hóa và được đo lường dưới dạng mức độ tự báo cáo về những khó khăn đã trải qua trong các tình huống giữa cá nhân với cá nhân và cá nhân với sự hoàn thành các công việc hằng ngày (Bochner, 1972, 1981; Furnham \& Bochner, 1982a, 1986; Taft, 1977 as cited by Wilson, 2013). Theo Wilson (2013) sự TNVHXH cũng liên quan đến lý thuyết học tập xã hội, cho thấy rằng hành vi của con người thu được chủ yếu thông qua việc bắt chước hành vi của người khác hơn là thông qua học tập cá nhân. Kể từ khi khởi đầu, SCAS đã được sử dụng trong các chương trình nghiên cứu Tiếp biến văn hóa trong các lĩnh vực khác bao gồm truyền thông và ngôn ngữ học, giáo dục, kinh doanh quốc tế và quản lý, và tâm lý học tổ chức.

Gudykunst (1999) đã đánh giá SCAS như là một cơ sở có tính thực nghiệm nhất trong bất kỳ phương pháp đo lường nào được sử dụng trong nghiên cứu về các mối quan hệ liên văn hóa và coi nó là một thang đo đáng tin cậy, hợp lệ và linh hoạt về khả năng thích nghi hành vi.

\section{Sự phát triển và xác nhận thang đo SCAS-R}

Mặc dù SCAS được định nghĩa như là một thang đo về năng lực hành vi, thuật ngữ đã được sử dụng trong thang đo này có thể nắm bắt cảm xúc hơn là hành vi phản ứng đối với quá trình chuyển đổi giao thoa văn hóa (Wilson, 2013). Để giải quyết vấn đề này, Wilson (2013) phát triển việc định nghĩa khái niệm Sự TNVHXH như một khía cạnh hành vi về năng lực văn hóa bằng cách xây dựng một thang đo SCAS điều chỉnh (tên là SCAS-R). Nghiên cứu của Wilson (2013) cũng giải quyết một vấn đề khác đó là, mặc dù phần lớn các nhà nghiên cứu khác đã sử dụng SCAS như là một đại diện toàn thể của thích nghi văn hóa xã hội tức là họ đo lường nó theo cách đơn hướng nhưng một số nghiên cứu trước đây đã tìm thấy bằng chứng rằng Sự TNVHXH có thể có nhiều khía cạnh. Nên việc Wilson (2013) điều tra sâu hơn và điều chỉnh khái niệm SCAS theo hướng hành vi đa khía cạnh sẽ cho phép hiểu biết toàn diện hơn về cách năng lực hành vi thay đổi phụ thuộc vào các miền khác nhau của trải nghiệm cá nhân của người 
nhập cư trong xã hội khác văn hóa với họ. Rõ ràng phát triển một thang đo đa khía cạnh của SCAS sẽ cho phép điều tra và ứng dụng cụ thể hơn khái niệm Sự TNVHXH.

\section{Phát triển lý thuyết và phương pháp luận về SCAS-R}

Mục tiêu Wilson (2013) phát triển SCAS-R là tạo ra một thước đo về năng lực hành vi bao gồm nhiều khía cạnh thích nghi. SCAS-R đã được hình thành như một cách đo lường dạng tự báo cáo về sự thông thạo hành vi trong việc thích nghi với bối cảnh văn hóa mới. Năm khía cạnh của SCAS-R được Wilson (2013) đề xuất là: Giao tiếp cá nhân, Sở thích cá nhân và sự tham gia vào cộng đồng, Hiệu quả công việc hoặc học tập, Thông thạo ngôn ngữ và Thích nghi sinh thái. Thông tin tiếp theo tóm tắt vấn đề lý thuyết liên quan đến năm khía cạnh thích nghi này.

Một trong những khía cạnh đầu tiên được đề xuất, là Giao tiếp giữa các cá nhân. Sự phát triển về lý thuyết của khía cạnh Giao tiếp giữa các cá nhân bắt nguồn từ mô hình học tập xã hội. Học tập xã hội nói về cách hành vi học tập của từng cá nhân đạt được thông qua trải nghiệm và là các kết quả có được từ hành động, quan sát và bắt chước (Bandura, 1977). Cụ thể, những người trải nghiệm môi trường văn hóa mới thích nghi hành vi của họ, một phần, thông qua việc bắt chước hành vi của người khác như một cách để tăng kết quả tích cực và giảm hậu quả tiêu cực (Oberg, 1960; Torbiorn, 1982 as cited by Wilson, 2013). Lý thuyết học tập Xã hội liên tục cho thấy rằng những người nhập cư giữ lại thông tin về những kết quả hành vi này, từ đó thúc đẩy cơ hội tái tạo thành công hành vi trong các bối cảnh tương tự (Bandura, 1977).

Nền tảng lý thuyết cho khía cạnh Giao tiếp giữa các cá nhân được bổ sung thông tin từ vòng tròn đồng tâm của Masgoret và Ward (2006) mô tả ở Hình 1, trong đó Sự thông thạo ngoại ngữ và Năng lực giao tiếp là hai thành phần trung tâm của Tương tác liên văn hóa hiệu quả và rồi sau đó cấu thành khái niệm rộng hơn là Sự TNVHXH. Dựa vào vai trò lý thuyết này của năng lực ngôn ngữ trong khuôn khổ lý thuyết học tập văn hóa, hai mục hỏi đo lường mức độ tự báo cáo về sự thông thạo ngôn ngữ quốc gia của từng cá nhân (nói và hiểu) được Wilson (2013) đưa vào trong SCAS-R, và kết quả phân tích của Wilson (2013) cho thấy sự thông thạo ngoại ngữ tách khỏi giao tiếp giữa các cá nhân thành một khía cạnh mới, Wilson (2013) đặt tên là khía cạnh Thông thạo ngôn ngữ, khía cạnh này tồn tại song song với khía cạnh Giao tiếp cá nhân như một khía cạnh của sự TNVHXH.

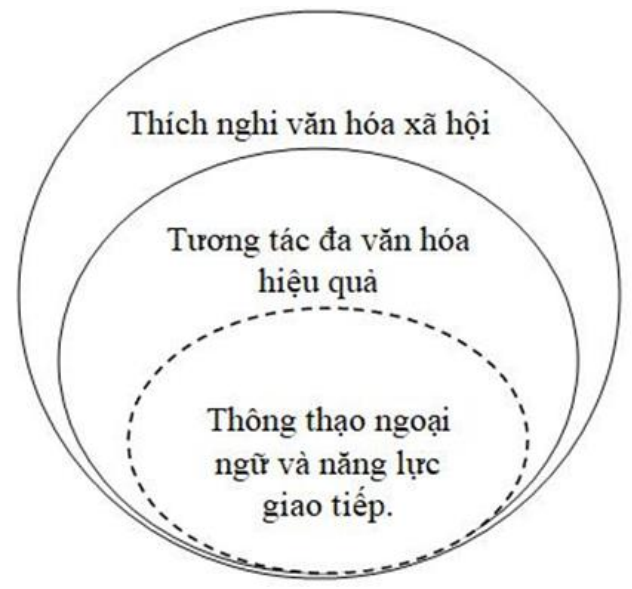

Hình 1. Mô hình vòng tròn đồng tâm về sự TNVHXH (Masgoret \& Ward, 2006) 
Sau đó, Wilson (2013) áp dụng khuôn khổ của khái niệm văn hóa sinh thái của Berry và Georgas (Berry, 2001; Berry et al., 1987; Georgas, 1988, 1993 as cited by Wilson, 2013) vào hai trong số năm khía cạnh thích nghi văn hóa xã hội được đề xuất, đó là hành vi của một cá nhân thích nghi với môi trường sinh thái chung và khả năng tham gia của một người với cộng đồng và duy trì sở thích của cá nhân. Hai khía cạnh này được đặt tên là Sở thích cá nhân và sự tham gia vào công đồng, và Thích nghi sinh thái.

Sự tham gia vào cộng đồng làm nổi bật các hành vi tham gia của cá nhân trong một xã hội mới. Cụ thể, lĩnh vực này nắm bắt được khả năng của một cá nhân trong các vấn đề sau: Phát triển và duy trì mạng lưới xã hội và tình bạn trong một môi trường văn hóa mới; tham gia và duy trì sự tham gia vào các hoạt động cộng đồng; và tiếp tục theo đuổi sở thích cá nhân của mình.

Sự tham gia vào cộng đồng có thể phụ thuộc rất nhiều vào khả năng tự tin và khả năng giao tiếp của một người nhập cư, vì thiếu kỹ năng giao tiếp sẽ gây ra nhiều hiểu lầm về văn hóa và giao tiếp (Masgoret $\& W$ ard, 2006) hoặc là rào cản đối với phát triển mối quan hệ với các thành viên trong xã hội (Clément \& Bourhis, 1996; Noels, Pon, \& Clément, 1996).

Còn Sư thích nghi sinh thái đo lường hành vi thích nghi của người nhập cư với môi trường xung quanh họ. Bronfenbrenner (1977) vạch ra bốn bối cảnh sinh thái quan trọng mà một cá nhân tương tác. Cấp độ đầu tiên, vi mô, liên quan trực tiếp đến con người và môi trường xung quanh như là nhà riêng hoặc nơi làm việc, trong khi mức độ thứ hai còn gọi là hệ sinh thái trung gian bao gồm các mối tương quan giữa các đối tượng khác nhau (e.g., tương tác giữa nơi làm việc, gia đình và bạn bè). Cấp độ sinh thái thứ ba, là hệ sinh thái bao gồm các cấu trúc xã hội chính thức hoặc phi chính thức như chính quyền, cộng đồng và cơ sở hạ tầng ảnh hưởng trực tiếp và gián tiếp đến các bối cảnh đã nói ở trên. Cấp bậc cuối cùng, hệ thống vĩ mô, phản ánh cấu trúc tổng thể của một nền văn hóa hoặc xã hội bao gồm cả các ý thức hệ ngầm (e.g., các giá trị văn hóa) và mô hình thể chế rõ ràng (e.g., quy định hoặc luật). Việc áp dụng mô hình của Bronfenbrenner vào SCAS-R ở khía cạnh Sự thích nghi sinh thái có thể cung cấp một cách thức để phân biệt các mức độ khác nhau trong bối cảnh của môi trường văn hoá mới người nhập cư đang tồn tại và năng lực của người đó được thể hiện trong các bối cảnh khác nhau đó.

Một khía cạnh tiềm năng cuối cùng được Wilson (2013) kiểm tra để đưa vào SCAS là tình huống học tập hoặc công việc. Học tập hoặc công việc được chọn để đưa vào SCAS-R bởi vì những người nhập cư thường di dời nơi ở do việc học tập hoặc cơ hội việc làm. Các nghiên cứu khác nhau đã được tác giả vận dụng để phát triển các mục hỏi đo lường khía cạnh thích nghi cụ thể này. Ví dụ, Pulakos, Arad, Donovan, và Plamondon (2000) đã xác định khía cạnh thích nghi văn hóa xã hội về hiệu suất liên quan đến khả năng thích nghi văn hóa trong công việc hoặc học tập. Khả năng thích nghi này đòi hỏi phải hiểu được nhu cầu và giá trị của các nhóm khác và các tổ chức, và khả năng của một cá nhân để sẵn sàng điều chỉnh hành vi của mình, ngoài lý do vì sự tôn trọng giá trị và phong tục của người khác.

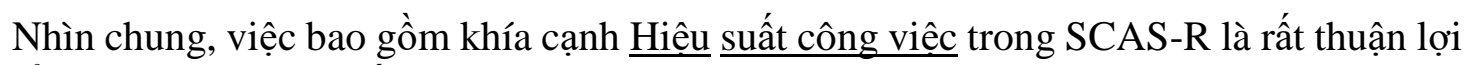
do tính tổng quát của tình huống người nhập cư là người di cư vì công việc và học hành.

Từ đó có thể tóm tắt là Wilson (2013) đã sửa đổi thang đo SCAS thành SCAS-R với năm khía cạnh xác định khái niệm Sự TNVHXH được mô hình như sau. 


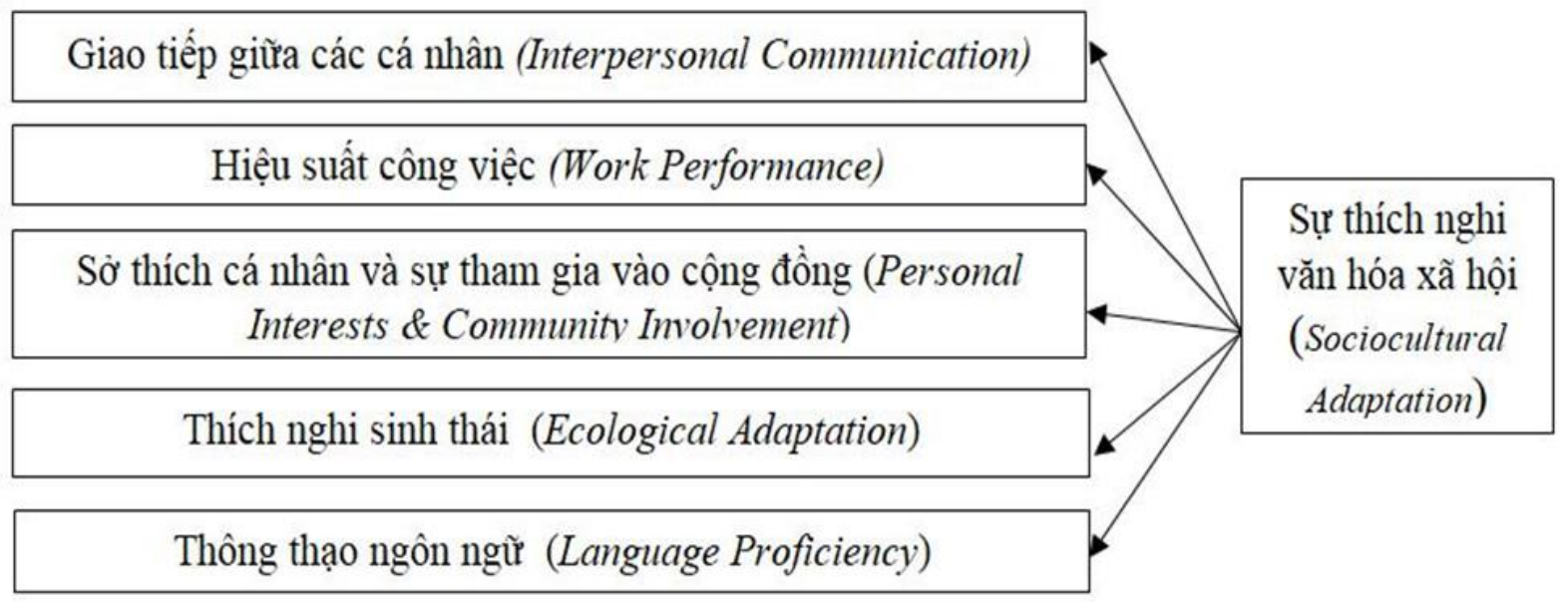

Hình 2. Mô tả giả thuyết H1 về mô hình đo lường khái niệm bậc hai Sự TNVHXH

Mục tiêu của công trình này là vận dụng thang đo SCAS-R của Wilson (2013) phát triển có điều chỉnh vào tình huống trí thức trẻ nhập cư vào TP.HCM, việc điều tra sâu về tính đa khía cạnh của sự TNVHXH có tính hành vi trong khuôn khổ tiếp biến văn hóa sẽ cung cấp thêm thông tin theo ngữ cảnh về những lĩnh vực văn hóa xã hội cụ thể mà quá trình thích nghi của người nhập cư đã diễn ra. Trong tình huống trí thức trẻ nhập cư vào TP.HCM, tác giả đặt giả thuyết là sự TNVHXH của họ cũng phù hợp với cấu trúc SCAS-R, cụ thể.

H1: Sự TNVHXH của trí thức trẻ nhập cư vào TP.HCM là khái niệm bậc hai được phản ánh qua năm khía cạnh thích nghi bậc nhất, (nhur mô tả ở Hình 2)

\section{Sự hài lòng về cuộc sống (Satisfaction with Life)}

Shin và Johnson (1978) đã định nghĩa Sự hài lòng trong cuộc sống là đánh giá toàn diện chất lượng cuộc sống của một người theo những tiêu chuẩn đã chọn của mình. Các phán xét về sự hài lòng phụ thuộc vào việc so sánh hoàn cảnh của một người với những gì được cho là một tiêu chuẩn thích hợp. Điều quan trọng là sự phán xét về mức độ hài lòng của mỗi người là dựa trên so sánh với tiêu chuẩn mà mỗi cá nhân đặt ra cho chính họ chứ không phải là từ áp đặt bên ngoài.

Diener, Emmons, Larsen, và Griffin (1985) đã thiết kế thang đo sự hài lòng với cuộc sống theo cách đo lường đa mục hỏi về quá trình xét đoán có tính tâm lý của một người đánh giá tổng thể cuộc sống của họ để có được một thước đo của sự hài lòng nói chung.

Khi di cư rõ ràng mục đích của người nhập cư là mưu cầu cuộc sống tốt đẹp hơn về các mặt họ lựa chọn, các công trình của Chirkov, Vansteenkiste, Tao, và Lynch (2007), Chirkov, Safdar, De Guzman, và Playford (2008) đã xác định các kết quả khác nhau của Sự TNVHXH là hạnh phúc chủ quan lớn hơn, sự hài lòng cuộc sống cao hơn và ít triệu chứng trầm cảm hơn. Từ đó tác giả đặt giả thuyết:

H2: Sụ TNVHXH có liên hệ thuận chiều với sụ hài lòng về cuộc sống của trí thức trẻ nhập cư vào TP.HCM 


\section{Sự phân biệt cảm nhận (Perceived discrimination)}

Cảm nhận về phân biệt đối xử liên quan đến kinh nghiệm chủ quan của một cá nhân về các hình thức đối xử không công bằng do tình trạng xã hội (e.g., như kinh tế xã hội, chủng tộc, giới tính). Những kinh nghiệm này có thể bao gồm việc bị từ chối các đơn xin nhập cư, không kiếm được việc làm, và bị ngược đãi bằng lời nói hoặc thể chất (Kessler, Mickelson, \& Williams, 1999). Một số lượng tương đối lớn các nghiên cứu đã được công bố về những ảnh hưởng của sự phân biệt đối xử đối với sức khỏe tâm lý của con người. Những nghiên cứu trên gợi ý rằng có mối quan hệ thuận giữa sự phân biệt cảm nhận được và trầm cảm, và có mối liên hệ nghịch giữa phân biệt đối xử với sự hài lòng trong cuộc sống và năng lực hành vi, ví dụ Pascoe và Richman (2009) nhận thấy mối liên hệ gián tiếp giữa sự phân biệt đối xử cảm nhận được và sự mãn nguyện về cả tinh thần và thể xác. Từ đó tác giả đặt giả thuyết là sự cảm nhận về phân biệt đối xử cao thì sự hài lòng với cuộc sống của người nhập cư sẽ giảm sút.

H3: Sự phân biệt cảm nhận có liên hệ ngược chiều với sụ hài lòng về cuộc sống của trí thức trẻ nhập cu vào TP.HCM

Những nghiên cứu đã được thực hiện về chủ đề này còn cho thấy cảm nhận rõ rệt hơn về phân biệt đối xử có liên quan đến nhiều khó khăn trong thích nghi hơn (Ataca \& Berry, 2002; Ward, 1996; Zlobina et al., 2006 as cited by Wilson, 2013) và giảm tần suất tiếp xúc với người bản địa (Leong \& Ward, 2000; Ward \& Leong, 2006 as cited by Wilson, 2013). Theo tổng hợp của Wilson (2013) cơ chế cơ bản của mối liên kết giả thuyết này có thể là: các cá nhân tự tin và quyết tâm có thể đánh giá các hành động phân biệt đối xử tiềm ẩn với họ như một sự căng thẳng hoặc khó khăn từ đó Wilson (2013) dự đoán rằng có một mối liên hệ nghịch chiều giữa sự phân biệt đối xử cảm nhận và TNVHXH.

Từ đó, tác giả xây dựng các giả thuyết về vai trò của sự phân biệt cảm nhận được với sự TNVHXH.

H4: Sự TNVHXH có liên hệ nghịch chiều với sự phân biệt cảm nhận

Kết hợp ba giả thuyết $\mathrm{H} 2, \mathrm{H} 3$ và $\mathrm{H} 4$ hình thành giả thuyết $\mathrm{H} 5$

H5: Sụ phân biệt cảm nhận được có vai trò trung gian trong mối quan hệ giữa Sụ TNVHXH và sụ hài lòng về cuộc sống của người nhập cu 


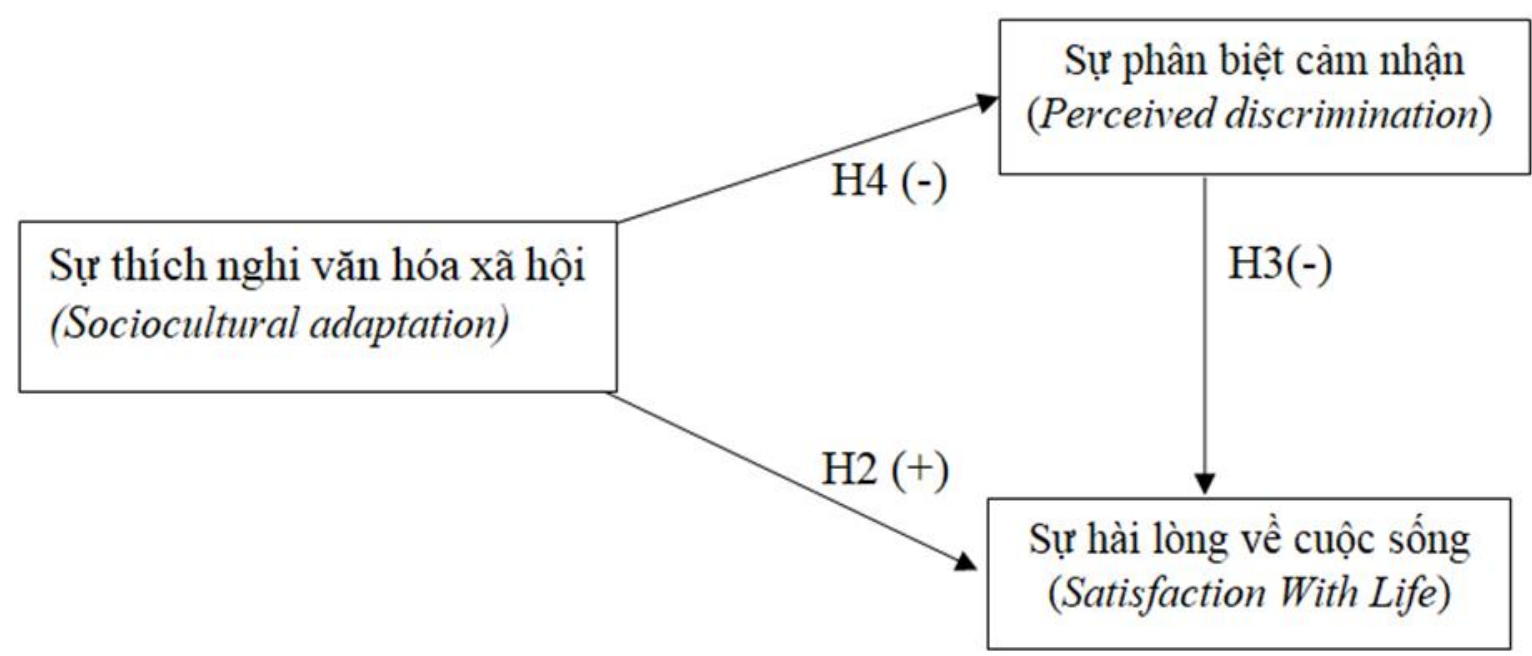

Hình 3. Mô hình cấu trúc đề xuất

\section{Đo lường và thiết kế thang đo so bộ}

Quá trình xây dựng thang đo sơ bộ của sự TNVHXH theo sát thang đo khái niệm đã được định hình trong nghiên cứu của Wilson (2013). Tất cả các phát biểu được chỉnh sửa từ ngữ nhờ quá trình phỏng vấn sâu ba trí thức (trong đó hai người là dân nhập cư từ 4 đến 10 năm và một người xem như là dân bản địa vì ông bà cha mẹ đã di cư đến TP.HCM vào những năm 1950 của thế kỷ trước. Kết quả cụ thể như sau:

Thang đo Giao tiếp giữa các cá nhân: tác giả chủ động loại khỏi thang đo này một phát biểu từ thang đo gốc là "Tôi thay đổi tốc độ nói của tôi cho phù hợp về mặt văn hóa" vì như đã lập luận tại cơ sở lý thuyết, các vấn đề liên quan đến thích nghi ngôn ngữ được tách ra thành một khía cạnh riêng của Sự TNVHXH. Các phát biểu còn lại chỉnh sửa ngôn từ Việt hóa cho dễ cảm nhận với người trả lời.

Thang đo Hiệu suất công việc và thang đo Sở thích của cá nhân và sự tham gia vào cộng đồng sử dụng nguyên văn thang đo gốc, chỉ chỉnh sửa từ ngữ qua quá trình dịch thuật.

Thang đo Thích nghi sinh thái được các đáp viên phỏng vấn sâu đề nghị giảm bớt phát biểu "Tôi đã quen với sự ồn ào ở nơi đây", vì nội dung của nó tích hợp nghĩa với các câu phát biểu khác mô tả tình trạng dân cư đông đúc và nhịp sống sôi động. Các câu còn lại được sử dụng nguyên văn thang đo gốc, chỉ chỉnh sửa ngôn từ qua quá trình dịch thuật.

Thang đo Thông thạo ngôn ngữ được điều chỉnh và phát triển nhiều nhất so với thang đo gốc của Wilson (2013) vì bối cảnh hai cuộc nghiên cứu khác nhau. Nghiên cứu này tìm hiểu việc nhập cư giữa các địa phương trong cùng quốc gia Việt Nam còn cuộc nghiên cứu của Wilson (2013) tìm hiểu việc nhập cư từ nước khác vào New Zealand, do đó tác giả chủ động loại bỏ câu phát biểu "Đọc và viết được ngôn ngũu nước chủ nhà" trong thang đo SCAS-R. Còn câu phát biểu "Nghe và nói được ngôn ngữ nước chủ nhà" được phát triển thành hai mục hỏi riêng. Câu phát biểu "Ở TP.HCM, tôi nói theo giọng miền Nam khi giao tiếp với người khác" được xây dựng mới hoàn toàn theo góp ý của các đáp viên của quá trình nghiên cứu định tính. 
Cho nên thang đo khái niệm Thông thạo ngôn ngữ này có thể xem là điểm mới về SCAS-R trong bối cảnh trí thức trẻ nhập cư TP.HCM.

Thang đo Sự phân biệt đối xử cảm nhận của nghiên cứu này sử dụng phiên bản có sửa đổi của thang đo phân biệt cảm nhận được của Williams, Spencer, và Jackson (1999) đo lường trải nghiệm thường ngày của cá nhân hoặc việc bị đối xử bất công vì vấn đề chủng tộc hoặc dân tộc của họ. (1985).

Thang đo Sự hài lòng cuộc sống vận dụng nguyên văn thang đo của Diener và cộng sự

\section{Thu thập dữ liệu}

Bảng câu hỏi được hoàn thành từ nghiên cứu định tính được phỏng vấn nháp trên mười người trả lời để hoàn thiện câu chữ và cách hành văn. Bảng câu hỏi chính thức được đưa ra khảo sát theo phương pháp thuận tiện trên các trí thức trẻ nhập cư tại TP.HCM là học viên các lớp buổi tối tại Trường Đại học Kinh tế TP.HCM, vào tháng 3 năm 2018. Có 220 phiếu thu về, sau khi rà soát loại 14 phiếu không đạt yêu cầu (số câu bỏ trống chiếm quá $15 \%$ số câu hỏi của bản khảo sát), còn lại 206 phiếu được sử dụng cho phân tích định lượng.

\section{Phân tích định lượng}

Tác giả đánh giá chất lượng thang đo và kiểm tra giả thuyết nghiên cứu bằng mô hình phương trình cấu trúc PLS-Sem trên phần mềm Smart PLS 3. Quá trình đánh giá khái niệm bậc hai Sự TNVHXH sử dụng thủ tục lặp lại mục hỏi, có yêu cầu cơ bản là các khía cạnh bậc nhất của khái niệm nên có số mục hỏi cân bằng nhau, nên tác giả sẽ dùng số thống kê Cronbach's Alpha để đánh giá sơ bộ từng khái niệm bậc nhất của thang đo Sự TNVHXH theo định hướng số mục hỏi của các khái niệm bậc nhất sẽ được cân đối là ba mục (vì khía cạnh Thông thạo ngôn ngữ và Thích ứng sinh thái hiện có ba mục hỏi).

Sau khi đánh giá Cronbach’s Alpha cho ba khía cạnh thích ứng kết quả đạt được như sau:

\section{Bảng 1}

\begin{tabular}{|c|c|c|c|}
\hline & Khía cạnh & Phát biểu bị loại & Lý do \\
\hline 1 & $\begin{array}{l}\text { Giao tiếp giữa } \\
\text { các cá nhân }\end{array}$ & $\begin{array}{l}\text { Tôi có thế "đọc" được cảm xúc của người } \\
\text { tôi đang giao tiếp khi sống tại TpHCM }\end{array}$ & $\begin{array}{l}\text { Cronbach's alpha sau khi loại } \\
\text { mục hỏi tăng } 0,709 \rightarrow 0,796\end{array}$ \\
\hline 2 & $\begin{array}{l}\text { Hiệu suất } \\
\text { công việc }\end{array}$ & $\begin{array}{l}\text { Tôi có thể thể hiện góp ý của tôi với đồng } \\
\text { nghiệp khi ở TpHCM }\end{array}$ & $\begin{array}{l}\text { Cronbach's alpha sau khi loại } \\
\text { mục hói tăng } 0,617 \rightarrow 0,670\end{array}$ \\
\hline 3 & $\begin{array}{l}\text { Sở thích cúa } \\
\text { cá nhân và sự } \\
\text { tham gia vào } \\
\text { cộng đồng }\end{array}$ & $\begin{array}{l}\text { Tôi vẫn duy trì những thói quen và sở } \\
\text { thích cũ của minh khi đến sống tại } \\
\text { TpHCM }\end{array}$ & $\begin{array}{l}\text { Để duy trì giá trị nội dung cho } \\
\text { ba mục hỏi còn lại, do đó } \\
\text { khía cạnh này đổi tên thành } \\
\text { Sự tham gia vào cộng đồng. }\end{array}$ \\
\hline
\end{tabular}

Nguồn: Kết quả phân tích dữ liệu của nhóm nghiên cứu 
Việc kiểm tra sơ bộ độ tin cậy của thang đo bằng Cronbach’s Alpha cũng được thực hiện cho nhóm thang đo Phân biệt cảm nhận và Sự hài lòng, kết quả là tác giả loại bỏ 2 phát biểu "Tôi bị đối xủ thiếu tôn trọng so với nhũng người không phải dân nhập cu"; "Tôi bị gọi tên một cách xúc phạm” vì Cronbach's Alpha lần lượt tăng từ $0,758 \rightarrow 0,775 \rightarrow 0,796$ theo tiến trình loại mục hỏi. Thang đo Sự hài lòng cuộc sống thể hiện độ tin cậy ổn thỏa.

Kết quả của quá trình này là khái niệm Sự TNVHXH được giả thuyết gồm năm thành phần: mỗi thành phần đo lường bằng ba biến quan sát, các thành phần này lần lượt được đặt tên là Giao tiếp giữa các cá nhân, Hiệu suất công việc, Sự tham gia vào cộng đồng, Thích ứng sinh thái và Thông thạo ngôn ngữ. Thang đo sự phân biệt cảm nhận được gồm bốn biến quan sát và Sự hài lòng về cuộc sống gồm năm biến quan sát. Mô hình tổng quát của nghiên cứu gồm bảy khái niệm bậc nhất và một khái niệm bậc hai được đo lường theo phương pháp tiếp cận lặp lại bởi mười lăm biến quan sát.

\section{Thống kê mô tả sơ bộ dữ liệu}

Tìm hiểu lí do chuyển đến sống tại TP.HCM của trí thức trẻ nhập cư thì phần lớn là do cơ hội việc làm (33,9\%), điều kiện kinh tế tốt hơn (20,3\%) và học tập $(24,6 \%)$. Bên cạnh đó còn một số lí do như tìm tương lai tốt hơn cho con, hay là kết hôn...

\section{Đánh giá mô hình đo lường và kiểm định giả thuyết nghiên cứu}

Bước 1: Sau khi xây dựng mô hình đường trên cửa sổ Smart PLS 3, lần chạy thuật toán cPLS đầu tiên thể hiện rằng khái niệm Sự tham gia vào cộng đồng gặp hiện tượng hệ số chuẩn hóa có giá trị lớn hơn 1 . Nguyên nhân là do thuật toán cPLS yêu cầu các giả định phù hợp cho các mô hình khái niệm dạng phản ánh và nó rất coi trọng những giả định này. Thuật toán cPLS sẽ tạo ra kết quả kiểu này nếu giả định không được đáp ứng. Trong trường hợp bị vi phạm giả định như thế này nhà nghiên cứu nên sử dụng thuật toán rPLS.

Bước 2: Tác giả giữ nguyên cấu trúc mô hình đường trên Smart PLS 3 và chạy thuật toán rPLS lần đầu tiên, kết quả là các hệ số tải (outer loading) của các mục hỏi PICI-3; WP-3; PD-2; SWL-2 (lần lượt là 0,$628 ; 0,594 ; 0,591 ; 0,653$ ) tuy lớn hơn 0,4 nhưng đều bé hơn ngưỡng 0,708 . Nhưng khi xem xét các giá trị $C R$ và $A V E$ của bốn thành phần tiềm ẩn Sự tham gia cộng đồng; Hiệu suất công việc; Sự phân biệt cảm nhận và Sự hài lòng với cuộc sống thì thấy chúng đều cao hơn các giá trị ngưỡng 0,7 và 0,5 nên tác giả giữ các mục hỏi này trong thang đo để bảo vệ giá trị nội dung (Hair, Hult, Ringle, \& Sarstedt, 2014). Căn cứ trên các bảng số liệu 1 và 2 có thể thấy các khái niệm tiềm ẩn của mô hình đều đạt các yêu cầu mà Hair và cộng sự (2014) đã liệt kê về độ tin cậy mục hỏi như (Outer Loading $>0,4)$; độ tin cậy tổng hợp $(0,7<\mathrm{CR}<0,9)$; tính giá trị hội tụ (AVE $>0,5)$; cũng như đạt tính giá trị phân biệt theo tiêu chuẩn của Fornell và Larcker (1981).

Bước 3: Phân tích riêng mô hình đường chỉ có mối quan hệ nhân quả giữa Sự TNVHXH và Sự hài lòng cuộc sống bằng thủ tục Boostrap (1000 mẫu phụ), kết quả kiểm định Boostrap chứng minh có mối quan hệ nhân quả giữa 2 biến. Như vậy giả thuyết $\mathrm{H} 2$ được ủng hộ, đồng thời tác giả đạt điều kiện để thực hiện thủ tục kiểm định vai trò trung gian của Sự phân biệt cảm nhận trong mô hình. 
Bước 4: Mô hình đường dẫn toàn diện được thiết lập lại trên SmartPLS 3 và thủ tục Boostrap 1000 mẫu phụ được thi hành. Kết quả cho thấy, hệ số đường dẫn giữa Sự TNVHXH và Phân biệt cảm nhận không có ý nghĩa thống kê. Giả thuyết H4 bị bác bỏ. Theo quy tắc của Hair và cộng sự (2014) có thể kết luận là Phân biệt cảm nhận không đóng vai trò trung gian trong mối quan hệ giữa Sự TNVHXH và Sự hài lòng cuộc sống, nghĩa là giả thuyết $\mathrm{H} 5$ cũng bị bác bỏ.

Bước 5: Tác giả loại bỏ đường dẫn Sự TNVHXH vào Phân biệt cảm nhận và chạy lại thủ tục Boostrap với 1000 lần lấy mẫu, các kết quả trực quan được trình bày trong Hình 4 với giá trị hệ số chuẩn hóa ghi phía trước, giá trị p-value của thủ tục kiểm định ý nghĩa thống kê của hệ số đường dẫn ghi trong ngoặc đơn (phần mềm dùng dấu chấm để phân cách thập phân).

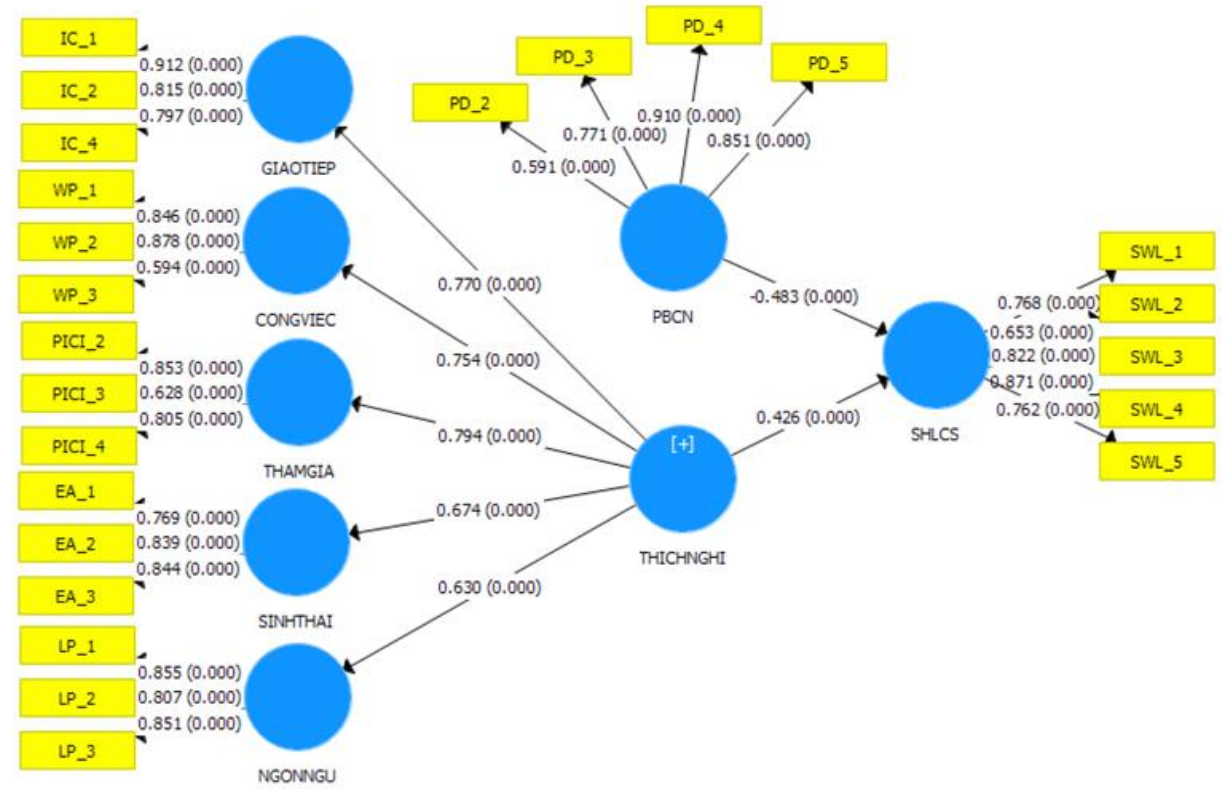

Hình 4. Mô hình PLS-Sem cuối cùng

\section{Kết luận}

Từ kết quả này có thể thấy rằng Sự TNVHXH của người nhập cư trí thức trẻ tại TP.HCM là khái niệm bậc hai phản ánh bởi năm khía cạnh thích nghi cụ thể là Giao tiếp giữa các cá nhân, Hiệu suất công việc, Sự tham gia vào cộng đồng, Thích ứng sinh thái và Thông thạo ngôn ngữ. Giả thuyết H1 được ủng hộ. Cụ thể hơn, trong năm thành phần thích nghi này, sự tham gia cộng đồng là thành phần quan trọng nhất thúc đẩy quá trình thích nghi của trí thức trẻ tại TP.HCM (hệ số đường dẫn lớn nhất: 0,794 ). Sự hài lòng cuộc sống của trí thức trẻ nhập cư tại TP.HCM sẽ bị giảm sút theo mức độ phân biệt đối xử họ cảm nhận được. Nhu vậy giả thuyết H3 được ủng hộ. Nhưng ngược lại sự TNVHXH của họ càng tốt thì sự hài lòng trong cuộc sống họ đạt được càng cao. Như vậy giả thuyết $H 2$ được ủng hộ. Mô hình nghiên cứu toàn diện thể hiện giá trị $\mathrm{R}^{2}$ của biến nội sinh đến Sự hài lòng cuộc sống là $42 \%$. 


\section{Bảng 2}

Độ tin cậy tổng hợp (CR), phương sai rút trích (AVE) và hệ số Cronbach's Alpha của các biến tiềm ẩn

\begin{tabular}{|l|r|r|r|}
\hline & Crombach's alpha & \multicolumn{1}{c|}{ CR } & AVE \\
\hline CONGVIEC & 0,678 & 0,822 & 0,613 \\
\hline GLAOTIEP & 0,796 & 0,880 & 0,711 \\
\hline NGONNGU & 0,789 & 0,876 & 0,703 \\
\hline PBCN & 0,801 & 0,866 & 0,624 \\
\hline SHLCS & 0,837 & 0,884 & 0,606 \\
\hline SINHTHAI & 0,752 & 0,858 & 0,669 \\
\hline THANGIA & 0,652 & 0,809 & 0,590 \\
\hline THICHNGHI & 0,858 & 0,884 & 0,343 \\
\hline
\end{tabular}

Nguồn: Kết quả phân tích dữ liệu của nhóm nghiên cứu

\section{Bảng 3}

Căn bậc hai AVE và hệ số tương quan giữa các biến tiềm ẩn

\begin{tabular}{|l|r|r|r|r|r|r|r|}
\hline & CONGVIEC & GIAOTIEP & NGONNGU & PBCN & SHLCS & SINHTHAI & THAMGIA \\
\hline CONGVIEC & 0,783 & & & & & & \\
\hline GIAOTIEP & 0,493 & 0,843 & & & & & \\
\hline NGONNGU & 0,392 & 0,334 & 0,838 & & & & \\
\hline PBCN & $-0,123$ & 0,192 & $-0,190$ & 0,790 & & & \\
\hline SHLCS & 0,391 & 0,040 & 0,388 & $-0,488$ & 0,779 & & \\
\hline SINHTHAI & 0,395 & 0,291 & 0,291 & $-0,092$ & 0,537 & 0,818 & \\
\hline THAMGIA & 0,450 & 0,631 & 0,307 & 0,156 & 0,226 & 0,480 & 0,768 \\
\hline
\end{tabular}

Nguồn: Kết quả phân tích dữ liệu của nhóm nghiên cứu

\section{Kết quả đóng góp}

Nghiên cứu này đã tổng kết lý thuyết về thang đo Sự TNVHXH và khẳng định những thành phần chính phản ánh sự TNVHXH của trí thức trẻ nhập cư tại TP.HCM. Đồng thời nghiên cứu cũng đã kiểm chứng các giả thuyết về mối tương quan giữa Sự TNVHX cũng như ảnh hưởng của Sự phân biệt cảm nhận được đến Sự hài lòng về cuộc sống của họ.

Thang đo sự TNVHXH được kiểm chứng có thể sử dụng như một công cụ để nghiên cứu sâu hơn ở các nghiên cứu tiếp theo trên các đối tượng khác ví dụ như người nhập cư lao động có tay nghề hay những sinh viên nhập cư vì mục đích học tập và tìm việc làm...hoặc là áp dụng cho những người nhập cư ở các tỉnh thành khác. 


\section{5. Đề xuất}

So với dân cư lâu đời TP.HCM thì người nhập cư thường chịu những thiệt thòi trong việc thụ hưởng những chính sách an sinh xã hội như y tế, giáo dục, nhà ở, điện, nước... Những người dân nhập cư cũng đã khá vất vả để hòa nhập với cuộc sống ở TP.HCM, không chỉ do rào cản từ những thủ tục hành chính và việc tiếp cận những phúc lợi xã hội, mà còn do đây đó vẫn có sự ứng xử ít thiện cảm với người nhập cư. “An cư mới lạc nghiệp", những trí thức trẻ nhập cư cung cấp nguồn lao động chất lượng cao, góp phần phát triển TP.HCM, chính vì thế, các nhà làm chính sách cần có những hành động cụ thể để có thể giúp họ hòa nhập tốt hơn, để TP.HCM trở thành nơi thu hút và phát huy tiềm năng con người. Do đó tác giả có những đề xuất như sau:

Người nhập cư là nguồn lực giúp TP.HCM phát triển một cách năng động, nên cần tuyên truyền và giúp người dân TP.HCM hiểu được vai trò của người nhập cư để có cách nhìn khách quan, cùng hợp tác trong cuộc sống và công việc. Điều này sẽ có lợi cho người nhập cư, người cư trú lâu đời và cho hoạt động kinh tế của TP.HCM.

Đảm bảo khả năng tiếp cận của người nhập cư đối với các cơ hội việc làm, các dịch vụ an sinh xã hội. Nếu khó khăn của người nhập cư được giải quyết không chỉ giúp cải thiện chất lượng cuộc sống của họ mà chính quyền cũng giảm các chi phí liên quan đến giải quyết những vấn đề xã hội phát sinh từ người nhập cư. Bên cạnh việc bảo đảm an sinh xã hội thì tạo dựng việc làm bền vững cũng là một trong các biện pháp giúp người nhập cư hòa nhập và gắn bó với đời sống mới.

Mặt khác, cần thu hút và tạo điều kiện để người nhập cư tham gia vào các hoạt động cộng đồng, hoạt động xã hội tại địa phương. Thực hiện điều này vừa giúp người nhập cư hòa nhập vào cộng đồng và cải thiện anh ninh xã hội vừa giúp bản thân người nhập cư ý thức được vai trò công dân của mình ở nơi cư trú mới.

Người nhập cư trí thức trẻ cần biết rằng tham gia cộng đồng gia tăng khả năng thích nghi của mình. Tham gia hoạt động cộng đồng giúp cải thiện kĩ năng giao tiếp, khả năng ngôn ngữ và thích nghi môi trường... Để "nhập gia tùy tục" các trí thức trẻ nhập cư cần tìm cách hòa nhập, không ngừng học hỏi những điều mới để phát triển bản thân trong môi trường TP.HCM.

Bên cạnh đó, ngoài những lí do chính đến TP.HCM vì kinh tế, thu nhập hay học tập thì tương lai cho con cái cũng là điều trí thức trẻ nhập cư quan tâm. Chính vì vậy, chính quyền thành phố cần có biện pháp hỗ trợ giáo dục, tạo điều kiện để mọi trẻ em nhập cư đều được đến trường ngay từ cấp nhà trẻ.

\section{Hạn chế của nghiên cứu và hướng nghiên cứu tiếp theo}

Nghiên cứu này chỉ tập trung vào đối tượng trí thức trẻ, do đó các nghiên cứu trong tương lai nên tiến hành điều tra thêm các đối tượng nhập cư khác vào TP.HCM để có cái nhìn tổng quát hơn. Và cần lấy mẫu lớn hơn, có tính đại diện hơn.

Áp dụng thủ tục cPLS với khái niệm tiềm ẩn dạng phản ánh sẽ cho kết quả ước lượng nhất quán hơn, đó là điều các nghiên cứu tương lai về chủ đề này cần chú ý. 


\section{Tài liệu tham khảo}

Bandura, A. (1977). Social learning theory. Oxford, UK: Prentice-Hall.

Bronfenbrenner, U. (1977). Toward an experimental ecology of human development. American Psychologist, 32(7), 513-531.

Chirkov, V. I., Safdar, S., De Guzman, J., \& Playford, K. (2008). Further examining the role motivation to study abroad plays in the adaptation of international students in Canada. International Journal of Intercultural Relations, 32(5), 427-440.

Chirkov, V. I., Vansteenkiste, M., Tao, R., \& Lynch, M. (2007). The role of self-determined motivation and goals for study abroad in the adaptation of international students. International Journal of Intercultural Relations, 31, 199-222.

Clément, R., \& Bourhis, R. Y. (1996). Bilingualismand intergroup communication. International Journal of Psycholinguistics, 12, 171-191.

Diener, E., Emmons, R. A., Larsen, R. J., \& Griffin, S. (1985). The satisfaction with life scale. Journal of Personality Assessment, 49(1), 71-75.

Fornell, C., \& Larcker, D. F. (1981). Evaluating structural equation models with unobservable variables and measurement error. Journal of Marketing Research, 18(1), 39-45.

Gudykunst, W. B. (1999). Theory and research on intercultural relations: An introduction. International Journal of Intercultural Relations, 23(4), 529-534.

Hair, J. F., Hult, G. T., Ringle, C. M., \& Sarstedt, M. (2014). A primer on partial least squares structural equation modeling (PLS-SEM) (1st ed.). Thousand Oaks, CA: SAGE.

Kessler, R. C., Mickelson, K. D., \& Williams, D. R. (1999). The prevalence, distribution, and mental health correlates of perceived discrimination in the United States. Journal of Health and Social Behavior, 40(3), 208-230.

Masgoret, A.-M., \& Ward, C. (2006). Culture learning approach to acculturation. In D. L. Sam \& J. W. Berry (Eds.), The cambridge handbook of acculturation psychology. Cambridge, UK: Cambridge University Press.

Noels, K. A., Pon, G., \& Clément, R. (1996). Language, identity, and adjustment: The role of linguistic self-confidence in the acculturation process. Journal of Language and Social Psychology, 15(3), 246-264.

Pascoe, E. A., \& Richman, L. S. (2009). Perceived discrimination and health: A meta-analytic review. Psychological Bulletin, 135(4), 531-54.

Pulakos, E. D., Arad, S., Donovan, M. A., \& Plamondon, K. E. (2000). Adaptability in the workplace: Development of a taxonomy of adaptive performance. Journal of Applied Psychology, 85(4), 612-624.

Searle, W., \& Ward, C. (1990). The prediction of psychological and sociocultural adjustment during cross-cultural transitions. International Journal of Intercultural Relations, 14, 449-464.

Shin, D. C., \& Johnson, D. M. (1978). Avowed happiness as an overall assessment of life. Social Indicators Research, 5, 475-492. 
Tran, M. T. T. (2013). Giáo trình tâm lý học người trưởng thành [Curriculum of adult psychology]. Ho Chi Minh, Vietnam: NXB Đại học sư phạm Thành phố Hồ Chí Minh.

Williams, D. R., Spencer, M. S., \& Jackson, J. S. (1999). Race, stress, and physical health: The role of group identity. In R. J. Contrada \& R. D. Ashmore (Eds.), Self, social identity, and physical health: Interdisciplinary explorations (pp. 71-100). New York, NY: Oxford University Press.

Wilson, J. (2013). Exploring the past, present and future of cultural competency research: The revision and expansion of the sociocultural adaptation construct. (Unpublished doctoral dissertation). Victoria University of Wellington, Wellington, New Zealand. 